\title{
The bottlenosed dolphin's (Tursiops truncatus) understanding of gestures as symbolic representations of its body parts
}

\author{
LOUIS M. HERMAN, DAVID S. MATUS, ELIA Y. K. HERMAN, MARINA IVANCIC, and ADAM A. PACK \\ Kewalo Basin Marine Mammal Laboratory, University of Hawaii, Honolulu, Hawaii \\ and The Dolphin Institute, Honolulu, Hawaii
}

\begin{abstract}
We assigned gestural symbols to nine body parts of a bottlenosed dolphin (Tursiops truncatus). The dolphin was first trained to touch any floating object it chose with the body part indicated by a gestural symbol. In Experiment 1, we tested the dolphin's ability to now touch specific gesturally referenced objects using specific gesturally referenced body parts. In Experiment 2, we tested its ability to either touch or toss gesturally referenced objects with gesturally referenced body parts or to simply display those body parts or shake them back and forth. The acts of touching, tossing, displaying, and shaking were each associated with specific gestures and appeared in random sequences within test sessions. The results demonstrated highly significant levels of performance throughout these tasks, including many successes on the first occasions of new body-part uses. These findings provided strong evidence that the gestural symbols we used for body parts were semantically processed and understood by the dolphin as representing those body parts.
\end{abstract}

An understanding that words represent things (e.g., objects, events, relations, locations) is fundamental to language (Gauker, 1990; Savage-Rumbaugh et al., 1993) and is sometimes termed referential understanding. Although this level of understanding seems self-evident for humans, the degree to which animals may come to understand symbols as representations is less clear. The early studies of language learning by chimpanzees (Pan troglodytes) (e.g., Gardner \& Gardner, 1971; Rumbaugh, 1977; Terrace, 1979) emphasized language production but failed to demonstrate that the symbols used by the animals were understood referentially, as representations of objects or events (Herman, 1987; Savage-Rumbaugh, 1984, 1986). Referential understanding can develop more easily through language-comprehensionapproaches in which symbols are used in a variety of contexts and combinations to direct the behavior of the animal (e.g., Herman, 1987; Herman, Richards, \& Wolz, 1984). The success of the bonobo chimpanzee (Pan paniscus) Kanzi in language learning was largely achieved through the use of a comprehension approach and revealed Kanzi's apparent understanding that words of spoken English, as well as abstract symbols, functioned representationally (Savage-Rumbaugh et al., 1993).

This research was supported in part by grants from the Earthwatch Institute to L.M.H. and A.A.P., by The Dolphin Institute, and by donations from Apple Computer, Inc., and Mitsubishi Corp. The authors thank Sheila Abichandani, Ali Elhajj, Tia Kollar, Glen Matlock, and Amy Miller for their help in Experiment 1 and with library research. Robert Uyeyama and Becca Cowan performed judgments of the dolphin's responses from the videotape record. Correspondence should be addressed to L. M. Herman, Kewalo Basin Marine Mammal Laboratory, 1129 Ala Moana Blvd., Honolulu, HI 96814 (e-mail: lherman@ hawaii.edu).
The work on language learning by bottlenosed dolphins (Tursiops truncatus) emphasized comprehension from the start (Herman et al., 1984). For the dolphin named Akeakamai, human gestures were assigned to objects, actions, relationships, and locations and were used in a variety of combinations and contexts. Combinations were used successfully as instructions to Akeakamai to carry out specific tasks, such as transporting one gesturally referenced object to another, and required that the dolphin take account of both the meaning of the gestures and the particular gestural sequence to determine which object was to be transported and which object was the destination.

Herman and Forestell (1985) provided strong evidence that gestures for objects were understood referentially. In that study, Akeakamai reliably reported whether or not a gesturally referenced object (e.g., a basket, surfboard, hoop, pipe, etc.) was present in her tank. Akeakamai thus demonstrated her understanding of symbolic references to absent objects, one of the hallmarks of human referential understanding (Bronowski \& Beluggi, 1970; Hockett, 1960; Terrace, 1984). Additional evidence for referential understanding of gestural symbols was given by Herman, Pack, and Morrel-Samuels (1993), who summarized the different contexts and functions in which particular gestural symbols were understood by Akeakamai. Furthermore, indicative gestures (the human's pointing gesture toward an object) were interpreted by Akeakamai as references to objects as reliably as were the particular gestural symbols for those objects (Herman et al., 1999). In contrast, studies with chimpanzees and orangutans (Pongo pygmaeus) have typi- 
cally failed to show that these apes understand the referring function of the human manual pointing gesture toward distal objects (Call \& Tomasello, 1994; Povinelli, Reaux, Bierschwale, Allain, \& Simon, 1997; SavageRumbaugh, 1986). Chimpanzees can, however, learn to use their own pointing gestures as a reference to distal objects (e.g., Leavens \& Hopkins, 1998).

The present paper focuses on whether an animal can learn to understand symbolically presented self-references. In particular, can an animal understand that symbols can represent its own body parts? Children, even at the relatively young age of 2 , can point to as many as 20 of their different body parts in "show me" interchanges with a caregiver (MacWhinney, Cermak, \& Fisher, 1987; Witt, Cermak, \& Coster, 1990). These young children can also carry out a variety of verbal instructions referring to their body parts (e.g., "wash your hands," "brush your hair," "push the ball with your foot"), thereby demonstrating that they understand that words can refer to or represent their body parts.

The studies of language learning by apes have in a few cases used symbols for various body parts of their subjects; however, no formal investigation of whether the symbols were understood as representing those body parts has been carried out. Savage-Rumbaugh et al. (1993) presented a corpus of over 600 verbal instructions given to Kanzi, but no more than 10 of these included a body-part reference. Furthermore, even for those few, the references were almost always to the body parts of others rather than to Kanzi's body parts (e.g., "brush the doggie's teeth," p. 149; "wash Rose's hand," p. 164; “can you brush Liz's hair?" p. 197) and were often context limited or accompanied by vigorous prompting ("error correction"). Terrace (1979) reported only five bodypart names in the receptive vocabulary of 200 items of his chimpanzee Nim, but there was no attempt to establish the level or kind of understanding of body parts achieved by Nim. Patterson and Cohn (1994) gave several anecdotal accounts of the gorilla Koko responding to the spoken words "eye," "head," or "nipple" by touching the body part or by giving the gestural symbol for the part; but, again, there were no formal tests for referential understanding of those words.

Of course, none of this means that apes cannot develop referential understanding of body-part namesonly that it has not been conclusively demonstrated or specifically studied in any detail. What would provide sufficient evidence for an understanding by animals that symbols can represent body parts? Consider, for example, a dog lifting or extending its paw in response to the spoken instruction "give me your paw." We would not conclude from this that the dog understands that the word "paw" refers to its paw. The distinction is thus between an understanding of symbols as references to body parts and their use as discriminative stimuli for eliciting a response with a particular body part.

To infer that an animal (or young child) understands that symbols can represent its body parts at least three conditions must be met: (1) Different body parts must be associated with different symbols (e.g., "hand" vs. "foot"), (2) different symbolically referenced body parts must be used in the same way (e.g., "push the ball with your hand," and "push the ball with your foot"), and (3) the same symbolically referenced body part must be used in different ways (e.g., "shake your hand," and "push the ball with your hand"). An inference that the animal understands symbols as representations of its body parts is strengthened under Conditions 2 and 3 if the animal is able to use its body parts in novel ways in response to a symbolic reference, especially on the first occasion that the use is requested.

To meet the stated conditions successfully, the symbolically referenced body parts must be used flexibly in diverse ways, depending on the attachment of the bodypart symbols to additional symbols referring to actions. Conditions other than these three might be identified as implying referential understanding, but the three listed, if successfully demonstrated, are sufficient to infer that the subject understands that the symbol represents its body part.

Several studies of dolphins, together with observations from less formal procedures, suggest that dolphins may learn to understand that symbols can represent their body parts. For example, in most facilities housing dolphins, husbandry practices require the dolphins to display various body parts for inspection by trainers or veterinarians. At our laboratory, all of our dolphins reliably display the dorsal fin, pectoral fins, belly, sides, genital region, and tail flukes and open the mouth in response to specific gestural signals. However, this alone is not sufficient evidence to conclude that these body parts are understood referentially, because each body part is used in only one way and in one context.

Other evidence suggesting that dolphins may be able to understand symbolic references to their body parts comes from studies at our laboratory showing that the dolphin Elele was able to use any of three different body parts (her rostrum, pectoral fin, or tail) to touch a specified object or to toss it (Mercado, Uyeyama, Pack, \& Herman, 1999). The object (any one of five), the body part, and the particular action were each referred to by unique gestural signs and were understood reliably in all combinations when given in the sequence object name + body-part name + action name. A gestural sign glossed as shake was also familiar to Elele, but its prior use elicited only a back-and-forth movement of her rostrum (beak).

Other studies at our laboratory have relevance for demonstrating body-part awareness rather than for demonstrating the understanding of symbolic references to various body parts. These studies (reviewed in Herman, in press, and Herman et al., 1993) have demonstrated a dolphin's ability to imitate the motor behaviors of another dolphin. For example, in formal imitation studies, an observer dolphin will perform a somersault or will wave its pectoral fin after seeing a "demonstrator" dolphin perform those acts. Furthermore, the dolphin will imitate acts of a human demonstrator; for example, if the human raises his/her leg in the air, the dolphin will 
raise its tail, and if the human moves his/her head side to side or up and down, the dolphin will do the same. To accomplish these imitative acts, the dolphin must relate its body image to the body plan of the demonstrator, creating analogies, if necessary, for those behaviors demonstrated by a human (e.g., the dolphin's tail is analogous to the human's leg). Body-part awareness (e.g., Bermudez, Marcel, \& Eilan, 1995) obviously plays a part in most imitative acts and seems necessary for an understanding that symbols can represent one's own body parts. In humans, body-part awareness seems to be mediated by a central representational system that allows for conscious awareness and conscious control of one's own body parts, as in identifying a body part on request or deliberately reaching for an object (Coslett, 1998; Gallagher, $1986,1995)$. This system is separate from the system that controls unconscious motor acts, such as postural control.

In the experiments reported here, we examined whether the dolphin Elele could develop referential understanding of her different body parts, by demonstrating various uses of those body parts in response to gestural symbols. For example, we asked Elele, through different sequences of symbolic gestures, to display her dorsal fin, to shake it, or to use it to touch a basket or to toss a Frisbee. The ability of the dolphin to carry out these various body-part tasks reliably would meet the three criteria stated earlier and would thereby provide strong evidence for an understanding of symbols as references to her body parts.

\section{EXPERIMENT 1}

In Experiment 1, we tested Elele's ability to understand sequences of gestural signals requiring her to use a particular one of nine different body parts to touch objects. The particular object, the particular body part, and the touch action were each referred to through unique symbolic gestures. Pictorial representations of some of the types of hand and arm gestures used can be found in Herman et al. (1984, Figure 3).

\section{General Method}

Subject. Elele was a 14-year-old female bottlenosed dolphin (Tursiops truncatus). She and three other bottlenosed dolphins were housed together in two interconnected, circular, outdoor seawater tanks (each $15.2 \mathrm{~m}$ in diameter and $1.8 \mathrm{~m}$ in depth) at the Kewalo Basin Marine Mammal Laboratory in Honolulu. Test sessions with Elele were conducted in one of these tanks. She was fed approximately $9 \mathrm{~kg}$ of freshly thawed fish daily, receiving a portion of this diet during her daily test sessions. Elele had been a subject previously in experiments on cross-modal perception (Herman, Pack, \& Hoffmann-Kuhnt, 1998; Pack \& Herman, 1995) and on awareness of her own behaviors (Mercado, Murray, Uyeyama, Pack, \& Herman, 1998; Mercado et al., 1999). The prior Mercado et al. studies, as well as prior husbandry training for display of particular body parts to facilitate medical examinations, gave Elele some prior experience with body-part references and facilitated training for the present experiments.

Body parts. Figure 1 shows the nine dolphin body parts that we referred to symbolically: rostrum (beak), mouth, melon, dorsal fin, pectoral fin, side, belly, genitals, and tail. Furthermore, we referred differentially to the dolphin's left and right pectoral fin and to her left and right side. Elele was already familiar with gestural references to all of the body parts shown in Figure 1, except for melon, and would display those body parts when the body-part gesture was followed by a gesture glossed as display. Melon was newly introduced for this study, using a new gesture. Elele learned in a single training session to expose her melon reliably in response to the new gesture. As was noted earlier, Elele was also familiar with gestural references to various objects, to the actions touch and toss, and to the three-part sequence object name + body-part name + action name, which directed her to take the named action to the named object using the named body part. However, this sequence had been tested previously only with the body parts rostrum, pectoral fin, and tail (Mercado et al., 1999). We also noted earlier that the gestural sign shake was familiar to Elele only as an instruction to move her rostrum back and forth.

Objects. Five "baseline" objects were used throughout Experiment 1: ball (a black-and-white soccer ball), basket (a brown plastic laundry basket kept afloat by four small attached buoys), cone (an ordinary orange traffic cone with a Styrofoam insert to keep it afloat), Frisbee (an ordinary plastic Frisbee), and surfboard (a white, foam "body board" $1.1 \mathrm{~m}$ long). Each object was referred to by a unique symbolic gesture. During test trials, these objects were placed in random locations in the approximate half of the tank closest to Elele and were allowed to float freely about.

Three additional objects, each also referred to by a unique gesture, were used in object transfer tests: water (a stream of water

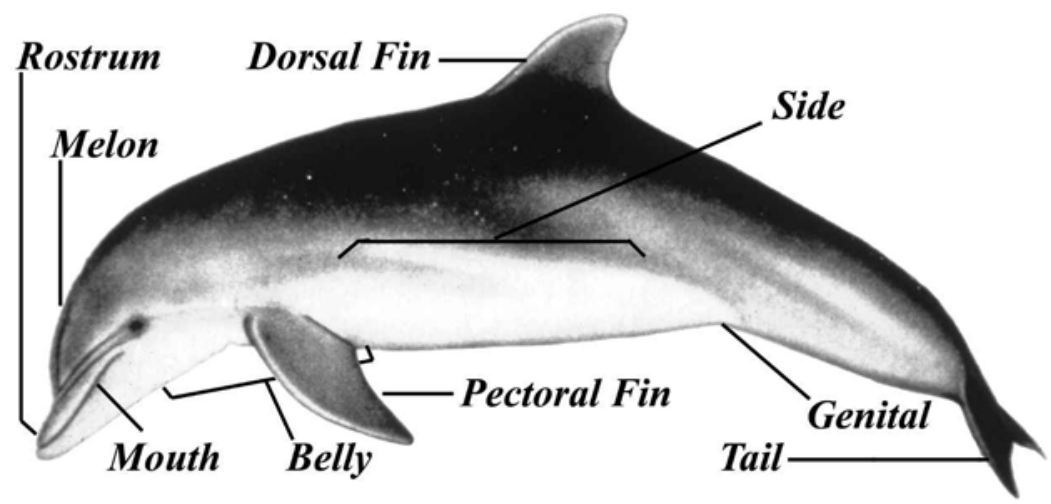

Figure 1. Artist's rendering of a bottlenosed dolphin showing the body parts referred to in this study. Drawing by Barbara Stolen (courtesy of Sam Ridgway). 
pouring into the tank from a garden hose attached to the tank wall), Hiapo (the 14-year-old male companion bottlenosed dolphin that habitually associated with Elele), and person (a person sitting on the wall of the tank with both feet in the water). These three were termed translocatable objects because, although they remained in a fixed location throughout a test session, their locations were changed across sessions.

Procedure. Training for using body parts in addition to rostrum, pectoral fin, and tail to touch objects was accomplished using body part + touch sequences only (i.e., the use of object gestural names and the toss response were reserved for later transfer tests). In addition, the trainer's raised leg (leg) was used to refer to Elele's tail, as a "synonym" for the manual gesture tail. Elele had never before used the leg lift in combination with other gestural signs. Left and right pectoral fin each used the same gestural sign but were differentiated by whether the trainer used his/her left or right arm when producing the sign. Left and right side were also distinguished only by whether the trainer used the left or right arm when signing. In each case, the dolphin responded with the body part on the same side as the trainer's arm (i.e., the "mirror-image" side).

During training, only objects that had no gestural names were present in Elele's tank (i.e., the baseline objects were not used), and Elele was free to touch any of these objects. Generally, all of the body parts were referred to at each training session and were given in a pseudorandom sequence. Elele's only difficulty was in responding reliably to left pectoral fin and left side. The right pectoral fin and right side tended to be used instead. Thus, during training, Elele was $70.1 \%$ correct in response to left-pectoral-fin touch $(n=$ $274)$ and $82.7 \%$ correct in response to right-pectoral-fin touch $(n=$ 110) $\left[\chi^{2}(1, N=274)=7.50, p<.01\right]$. Similarly, Elele was correct on $76.8 \%$ of left-side touch trials $(n=220)$ and $83.7 \%$ of right-side touch trials $(n=141)$, although these differences were not statistically significant. All other body parts were used correctly on $83 \%$ or better of the training trials.

Transfer tests immediately followed the completion of training and were conducted in three parts. In Experiment 1A, only the five baseline objects (ball, basket, cone, Frisbee, and surfboard) were present in the dolphin's tank. Experiment 1A was thus the first occasion when body parts other than rostrum, pectoral fin, and tail were referenced in the three-part sequence object + body part + touch. In Experiment 1B, the three translocatable objects, Hiapo, person, and water, were added to the object set so that there were now eight objects present at once. All body parts were referred to in Experiments $1 \mathrm{~A}$ and $1 \mathrm{~B}$, including left side, right side, left pectoral fin, and right pectoral fin. Finally, in Experiment 1C, we tested Elele's ability to use referenced body parts to touch baseline objects that were now suspended in the air rather than floating on the water surface. However, left and right were no longer used to prefix pectoral fin and side.

\section{Experiment 1A}

Elele's ability to touch the referenced baseline object (of five different objects) with the referenced body part was tested.

\section{Method}

At each of five testing sessions, one per day, there were 12 object + body part + touch test trials and 10 "filler" trials interspersed among the body-part trials. Filler trials consisted of a gestural reference to an object followed by a gestural reference to one of three actions: over ("leap over an object"), under ("swim under an object"), and spit ("squirt water from the mouth at an object"). For example, basket + over means "jump over the basket." Filler trials thus did not require touching the object with a body part, were highly familiar to Elele, and were almost always responded to correctly.
Filler trials therefore helped to ensure a relatively high level of overall correct responding by Elele and also served to prevent her from expecting only body-part trials.

At each session, each body part was referenced once, and each object was referenced either two or three times during the three-part sequences. Therefore, over the five sessions, each of the 60 unique combinations of the five objects and 12 body parts occurred exactly once. Test session schedules were arranged so that the same object was not referred to on successive trials.

To begin a trial, the trainer, who stood on a platform adjacent to the tank wall with head, arms, and torso visible to the dolphin, raised a bent arm with index finger extended. This was a familiar "pay attention" signal. In response, Elele stood on her tail, head out of the water facing the trainer. A supervisor, located on an elevated deck adjacent to the tank and out-of-view of the dolphin, signed to the trainer the sequence of gestures planned for that trial. On a verbal signal from the supervisor, the trainer began signing to the dolphin. While signing, the trainer wore opaque goggles to guard against eye-gaze cues that might guide the dolphin's response and to prevent the trainer from knowing what actions the dolphin was taking.

An observer located on the deck, and having no knowledge of the planned schedule or what the trainer had signed, labeled the dolphin's response vocally, using the appropriate grammatical structure. Depending on whether the observer's label matched the behavior required by the trainer's gestures, the supervisor verbally indicated to the trainer that the dolphin's response was correct or incorrect. Correct responses were rewarded with social praise. Additionally, fish reward was given on a variable ratio schedule averaging one fish every 2 or 3 correct trials. If the response was incorrect, the trainer simply called the dolphin back to the testing station by splashing the tank water with his/her hand. Intertrial intervals were a minimum of $25 \mathrm{sec}$, whether the response was correct or not. Assistants maintained a written record of each session and videotaped all trials to provide an archival record.

\section{Results and Discussion}

The left-hand column of Figure 2 gives examples of the dolphin's touch responses to three different baseline objects (ball, basket, Frisbee) using three different body parts (side, belly, melon). The clarity of the responses is apparent.

There were only two errors on the 50 filler trials. Each error was a choice of the wrong object. Elele's performance over the 60 object + body part + touch test trials given is summarized in Table 1; shown is the number of correct responses to the object component, to the bodypart component, and to the entire sequence. The touch component is not shown, since this was always responded to correctly. The maximum possible score in each cell is 5, and the maximum possible score in each column total is 60 . Overall, Elele responded wholly correctly to 48 of the 60 sequences, by choosing the referenced object and touching it with the referenced body part. Of the 12 errors, 2 were a choice of the wrong object, and the remaining 10 were the use of the wrong body part, as summarized in Table 2 . Five of the 10 body-part errors were associated with left-right choices; in four instances, the right pectoral fin or right side was used when the left was referenced, and in the other instance, left side was used when right side was referenced. These errors thus fall within the same generic 


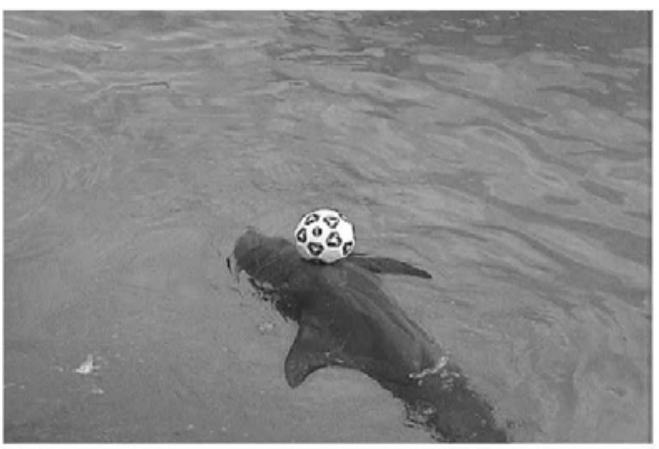

BALL SIDE TOUCH

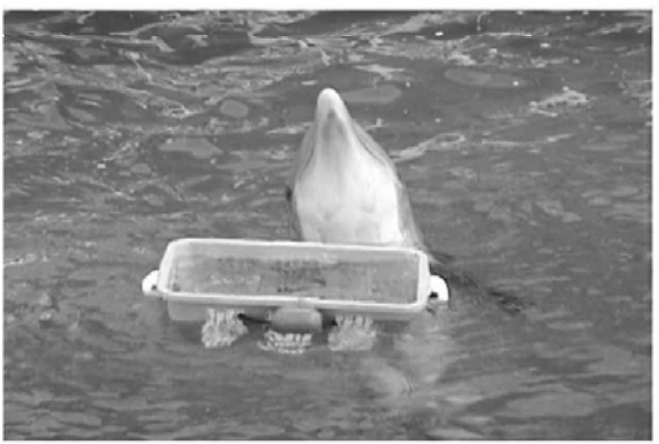

BASKET BELLY TOUCH

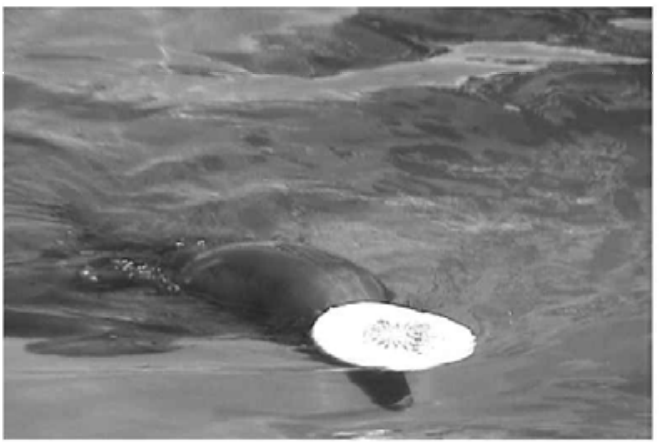

FRISBEE MELON TOUCH

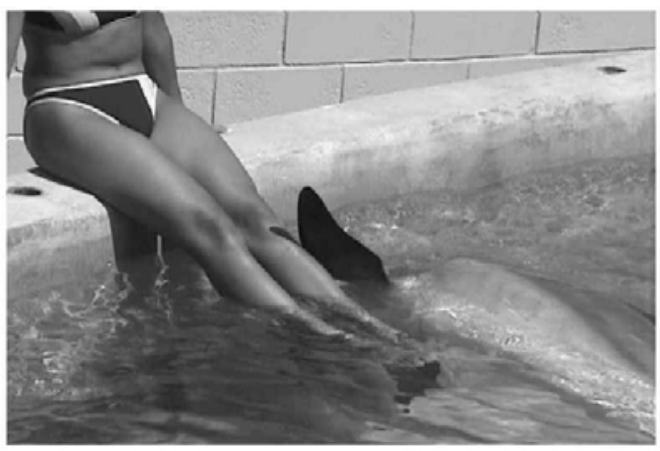

PERSON PEC FIN TOUCH

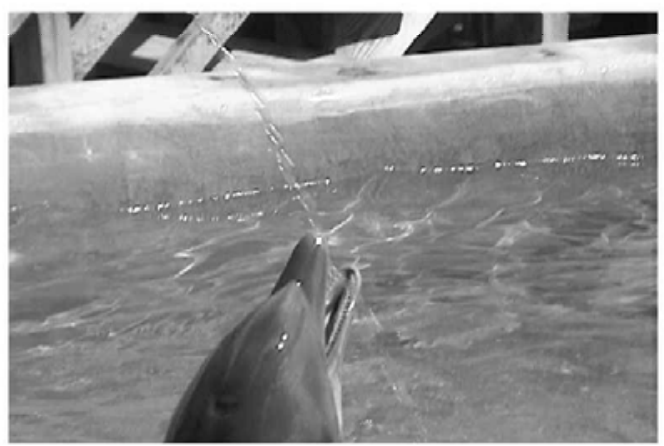

WATER MOUTH TOUCH

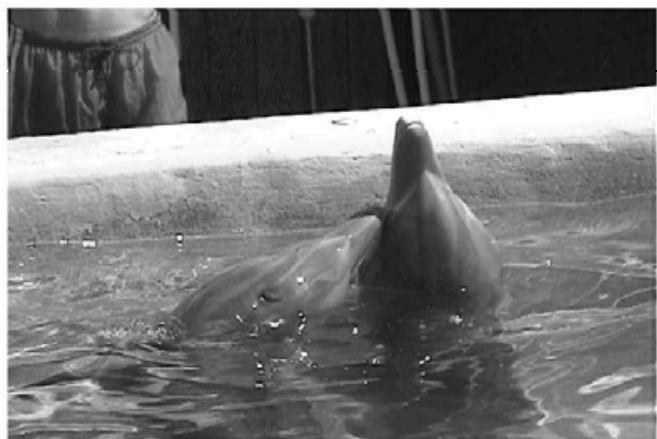

HIAPO ROSTRUM TOUCH

Figure 2. Examples of the dolphin Elele responding to object + body part + touch sequences in Experiments $1 \mathrm{~A}$ and $1 \mathrm{~B}$. The three left panels refer to responses to three different baseline objects using three different body parts. The three right panels refer to responses to each of the three translocatable objects using three different body parts. All panels are still images captured from individual frames of the digital video records obtained during testing.

body-part category as the referenced body part. Genital produced three body-part errors, two using tail and one using dorsal. Belly and leg each yielded one error, in each case an incorrect use of rostrum.

If the dolphin used the referenced body part on the very first occasion in which it appeared in an object + body part + touch sequence, a plus sign is shown in the body-part column of Table 1 . A minus sign in that column indicates that Elele used a different body part. The table shows that Elele used the referenced body part on 11 of the 12 first occasions $(p<.0001) .{ }^{1}$ As we noted earlier, Elele had prior experience in responding to threepart sequences involving rostrum, tail, and the generic pectoralfin, but not to sequences involving the remaining 10 body parts, including the specification of left or right pectoral fin and leg (recall that leg referred to the same body part as tail but had not been used before in a three-part sequence). Considering only those 10, Elele 
Table 1

Number of Correct Responses on Object + Body Part + Touch Sequences, for Three Object Classes, Shown by Component Parts of the Sequence for Each Listed Body Part, for Experiments 1A, 1B, and 1C.

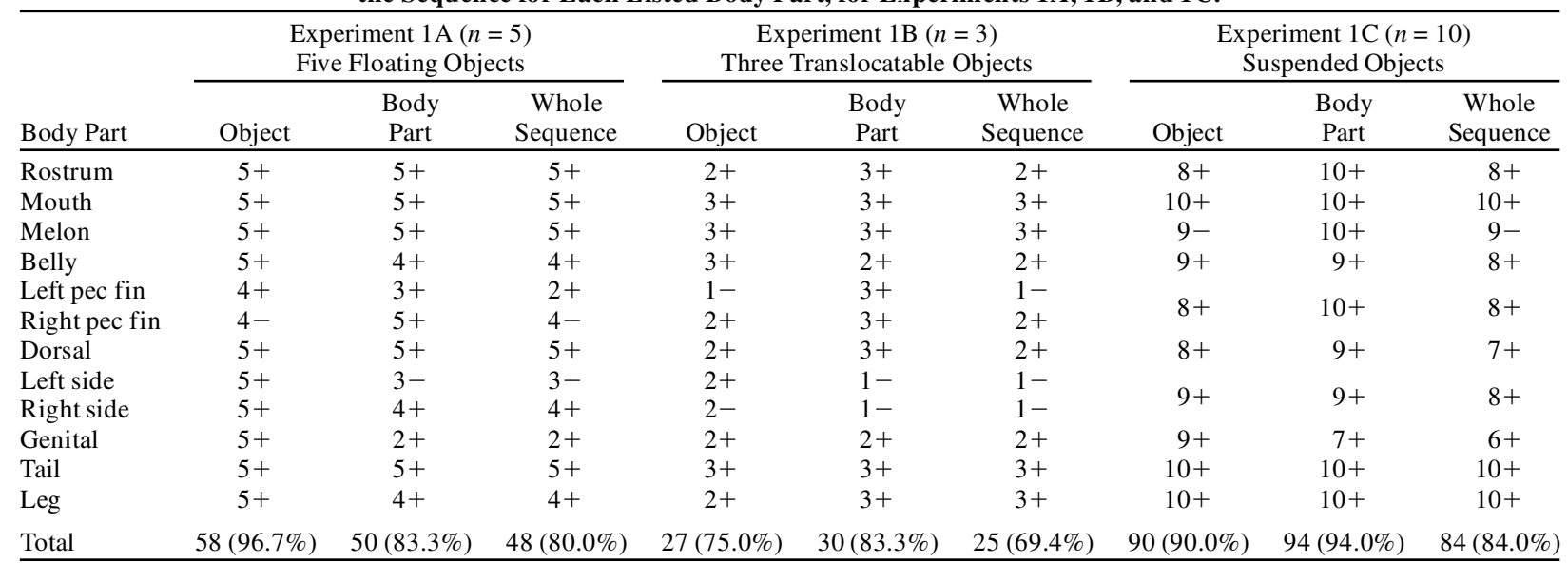

Note-Maximum possible scores are 5, 3, and 10 for Experiments 1A, 1B, and 1C, respectively. Data for touch are excluded (performance was 100\%). In Experiment 1C, left and right were no longer used. $\quad+$, correct response on first trial; -, incorrect response.

was still well above chance, using the referenced body part on 9 of 10 first occurrences $(p<.0001)$. Results for the first occasion in which particular whole sequences occurred are also shown in Table 1. Again, excluding rostrum and tail from the analysis, Elele responded wholly correctly on the first occurrence for 8 of the 10 threepart sequences using the remaining body parts $(p<$ $.0001)$.

The results of Experiment 1A thus established Elele's ability to use symbolically referenced body parts to touch symbolically referenced objects within object + body part + touch sequences. Body parts not previously referred to in these sequences were used successfully on the first occasion in which they appeared within a sequence, with the one exception of left side (right pectoral fin was used correctly on its first trial but was applied to the wrong object). Genital proved difficult overall but was used successfully on the first occasion in which it was referenced and on one other occasion. It is noteworthy that melon, a body part newly named for this study, was used successfully all five times that it was ref- erenced. The good results with tail and leg show that these two symbols functioned as synonyms, both referring to the dolphin's tail.

\section{Experiment 1B}

In Experiment 1B, we tested Elele's ability to transfer her touch responses with specific body parts to the three translocatable objects: person, water, and Hiapo. These three had been referred to previously in object + body part + touch sequences, but their use had also been restricted to rostrum, tail, and pectoralfin. None of the remaining body parts had been used previously with the three translocatable objects.

\section{Method}

The procedure was the same as that of Experiment 1A except that eight objects, rather than five, were present at each trial. The five baseline objects floated about in the tank, as in Experiment 1A. The three translocatable objects were arrayed along the tank wall, two to Elele's right and one to her left. The particular translocatable objects assigned to these locations varied each session, but, over sessions each object appeared equally often, or nearly so, at each lo-

Table 2

Body-Part Confusion Errors for Floating, Translocatable, and Suspended Objects in Experiments 1A, 1B, and 1C, Respectively

\begin{tabular}{llll}
\hline $\begin{array}{l}\text { Referenced } \\
\text { Body Part }\end{array}$ & Experiment 1A & \multicolumn{1}{c}{ Experiment 1B } & Experiment 1C \\
\hline $\begin{array}{l}\text { Belly } \\
\text { Left pec fin }\end{array}$ & $\begin{array}{l}\text { Rostrum (1) } \\
\text { Right pec fin (2) }\end{array}$ & Genital (1) & Genital (1) \\
$\begin{array}{l}\text { Left side } \\
\text { Right side }\end{array}$ & Right side (2) & Right side (2) & Tail (1) \\
Genital & Left side (1) & Left side (1), Right pec Fin (1) & Tail (1) \\
Leg & Tail (2), Dorsal (1) & Tail (1) & Tail (2), Belly (1) \\
Rostrum (1) & & - & - \\
Note-The number of times that a body part was used in error shown in parentheses (e.g., in Ex- \\
periment 1A, right side was used twice in error when the referenced body part was in fact left side. \\
Body parts not listed in the "Referenced Body Part" column were always used without error.
\end{tabular}


cation. During Experiment 1B, the dolphin Hiapo (Hiapo) remained with a trainer, who maintained him in a resting position at tankside during each trial. The individual acting as person sat on the tank wall with legs in the water and had no knowledge of what instruction was signed to Elele. The stream of water (water) from a hose suspended approximately $0.7 \mathrm{~m}$ above the tank wall sprayed outward into the tank about $1 \mathrm{~m}$.

There were 96 unique combinations of the 12 body parts and eight objects; each combination was tested once over the course of eight sessions. As in Experiment 1A, each session consisted of 12 body-part trials and 10 filler trials, arranged using the same rules as in Experiment 1A. Only one session was given per day; the eight planned sessions were completed over a 14-day period.

\section{Results and Discussion}

The right-hand column of Figure 2 gives examples of the dolphin's touch responses to the three different translocatable objects (person, water, Hiapo) using three different body parts (pectoral fin, mouth, rostrum). Again, the clarity of the responses is apparent.

Elele made only five errors on the 80 filler trials. Each error was a choice of the wrong object. Performance on object + body part + touch sequences for the translocatable objects is summarized in Table 1 . The maximum possible score in each cell is 3 , and the maximum score in each column is 36 . Again, the touch component is not shown, since the dolphin always responded by touching an object. Performance with the floating baseline objects is not shown but closely followed Elele's performance characteristics with baseline objects in Experiment 1A (Experiment 1B, 93.3\% correct choice of referenced object and $80.0 \%$ correct use of referenced body part). Overall, Elele used the referenced body part to touch a translocatable object on 30 of 36 trials. Three of the six errors involved left-right confusions, as shown in Table 2.

There were nine errors in 36 trials in choice of translocatable object: five errors on water trials, four on person trials, and no errors on Hiapo trials. Seven of these nine translocatable object errors were to other translocatable objects. Overall, baseline objects were selected correctly significantly more often than were translocatable objects $\left[\chi^{2}(1, N=84)=4.99, p<.05\right)$. There was no significant difference, however, in Elele's ability to use a referenced body part to touch a translocatable object and to touch a baseline object $\left[\chi^{2}(1, N=96)=0.02, p>.05\right]$.

It can be seen in Table 1 ("Whole Sequence" column) that Elele correctly used 9 of the 12 body parts to touch the referenced translocatable object on the first occasion in which the body part was referenced in that context $(p<.0001)$. This compares closely to her performance with the floating baseline objects in Experiment $1 \mathrm{~A}$, in which she correctly used 10 of the 12 body parts to touch the referenced floating object on the first occasion in which the body part was referenced $(p<.0001)$. Clearly then, Elele was approximately equally successful in responding with a referenced body part to either class of object. Thus, overall, Experiment 1B results demonstrated Elele's ability to transfer her touch responses with referenced body-parts from the floating objects to the translocatable objects.

\section{Experiment 1C}

The mechanics of the use of a body part to touch an object will vary depending on the location of the object relative to the individual. For example, touching an object on the floor requires very different motor actions than does touching an object located on a high shelf. In Experiment $1 \mathrm{C}$ we tested whether Elele was able to adapt the form of her body-part responses to a novel context, by touching baseline objects that were now suspended in the air rather than floating. To bring the referenced body part in contact with the referenced suspended object, Elele's movements and postures would have to be substantially altered from those used in responding to floating objects. Such alteration would tend to reveal more clearly her "intention" to respond with the referenced body part, rather than to simply perform a rote motor action.

\section{Method}

Because of Elele's difficulty with left-right discriminations in Experiments $1 \mathrm{~A}$ and $1 \mathrm{~B}$, we no longer required this discrimination in Experiment 1C. The trainer now gave the pectoral fin sign and the side sign only with the left arm. However, Elele was free to use either her left or her right body part in response. Altogether, 10 different gestural signs were used to reference nine of the dolphin's body parts (i.e., tail and leg each continued to refer to the dolphin's tail).

Only the five baseline objects were used for this test. During each trial, three of these objects were left floating freely in the tank, and the remaining two were suspended in the air from the elevated deck overlooking a section of the tank. Thin monofilament lines were used to maintain the bottom of each object approximately $25 \mathrm{~cm}$ above the water surface and approximately $91 \mathrm{~cm}$ out from the tank wall. This positioning made it possible for the dolphin to reach a suspended object with any body part and to have sufficient room to maneuver around the object, if necessary.

Each session consisted of 30 trials divided into five blocks of 6 trials. Within each block, there were four different body-part trials and two filler trials. Two of the body-part trials in a block referred to two of the three floating objects, and two other body-part trials referred to each of the two suspended objects. One filler trial referred to the third floating object, and the other referred to one of the two suspended objects. The same pair of objects was suspended throughout a block, but a different pair was used at each of the five blocks. The 10 possible unique pairings of the five objects were thus represented exactly once every two sessions. The complete test consisted of 10 sessions given over a 5-day period, for a total of 200 body-part trials and 100 filler trials. Each body part was associated with each object four times: twice while it was floating and twice while it was suspended. Across sessions, each of the suspended objects appeared in each of the two positions (left or right) an equal number of times.

\section{Results and Discussion}

Figure 3 contrasts the form of the dolphin's rostrum touch response to a floating object (Frisbee) and to a suspended object (cone). The two responses are different in form but not in function.

Performance with the suspended objects is summarized in Table 1. Elele responded correctly to 84 of the 100 unique three-part sequences. The majority of the sequence errors resulted from the choice of the wrong sus- 


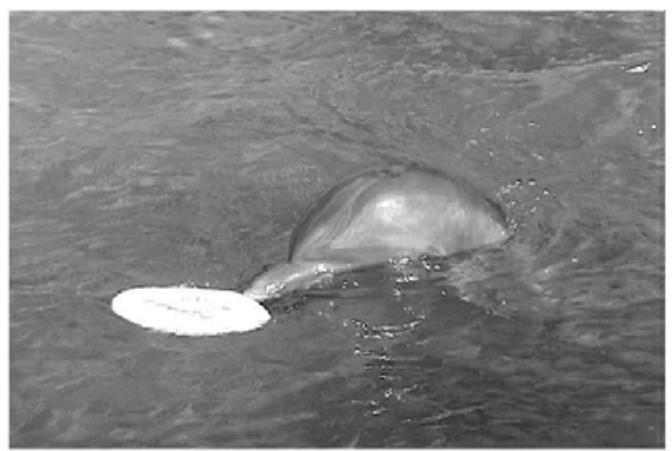

\section{FRISBEE ROSTRUM TOUCH (floating object)}

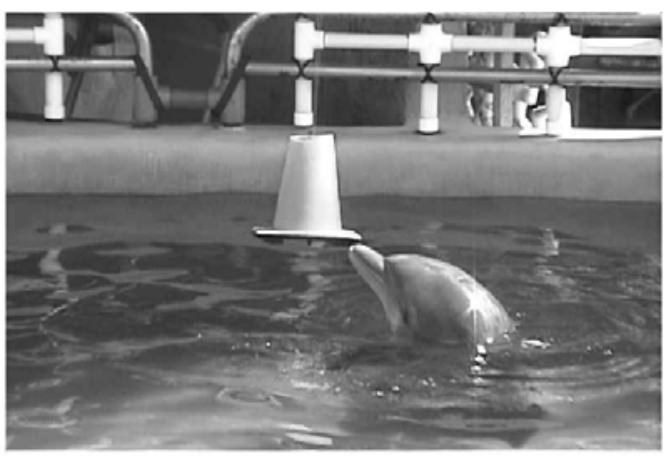

\section{CONE ROSTRUM TOUCH (suspended object)}

\begin{abstract}
Figure 3. Examples of the dolphin's different response topography when using its rostrum to touch a floating Frisbee (left panel) and a suspended cone (right panel) in response to object + body part + touch sequences in Experiment $1 \mathrm{C}$. Both panels are still images captured from individual frames of the digital video records obtained during testing.
\end{abstract}

pended object, although, overall, Elele's accuracy in choosing the referenced suspended object $(90$ correct choices in 100 trials) was well above chance $(p<.0001)$. There were only six body-part errors in the 100 sequences given. Elele's performance with floating objects in Experiment $1 \mathrm{C}$ is not shown Table 1, but it closely replicated that found in Experiment 1A: Elele responded correctly to 95 of the 100 sequences involving floating objects, significantly more correct sequences than occurred with suspended objects $\left[\chi^{2}(1, N=200)=6.44\right.$, $p<.05]$.

Most important, in Experiment 1C, Elele was approximately equally proficient in using the referenced body part to respond to suspended objects (94\% correct) and to floating objects (97\% correct). Her six body-part errors to suspended objects (four involving the use of her tail rather than the referenced body part) are listed in Table 2. She did respond correctly to each of the 10 different references to her body parts on her first attempt with suspended objects, although, in 1 of the 10 instances, she responded to the wrong suspended object. Altogether, these results established that Elele's use of particular body parts to touch objects in Experiments 1A and 1B was not dependent on stereotyped motor acts. Instead, she easily adapted her body-part touches to accommodate the particular condition of the designated object, suspended or floating.

\section{EXPERIMENT 2}

The results of Experiment 1 demonstrated Elele's ability to use different referenced body parts in the same way, by touching referenced objects. Her success satisfied Condition 2 for assessing referential understanding. In Experiment 2, we tested Elele's ability to use the same body part in different ways, to satisfy Condition 3. Specifically, we examined Elele's ability to take selectively any of four different symbolically referenced actions with symbolically referenced body parts: display the body part, shake it back and forth, touch it to an object (as in Experiment 1), or use it to toss an object. Touching, tossing, displaying, and shaking were each associated with a unique gestural symbol. We conducted the experiment in three parts. In Experiment 2A, we contrasted touch and toss responses. In Experiment 2B, we added the display response to the previous two. In Experiment $2 \mathrm{C}$, we added the shake response; thus, Experiment $2 \mathrm{C}$ contrasted all four responses: touch, toss, display, and shake.

\section{General Method}

The method was similar to that of Experiment 1. Tossing involved a vigorous movement of the referenced body part resulting in a physical displacement of the object. Touching involved merely bringing the named body part in contact with the object. Observers were usually able to discriminate tossing from touching easily. Display required the dolphin to expose the referenced body part above the water surface in front of the trainer. Shake required Elele to move the referenced body part back and forth or side to side.

\section{Experiment 2A}

In Experiment 2A, we contrasted responses to touch and toss. Elele was already familiar with the sequence object + body part + toss, but, as was the case for touch, its use had been restricted to her rostrum, tail, and pectoral fin. We had not formally tested tossing of objects with the remaining body parts before this study.

\section{Method}

The same nine body parts (10 symbols, counting both tail and $l e g$ ) and the same five baseline objects (floating only) were used as in Experiment 1. References to left or right body parts were again omitted. All five objects were available on all trials. Trials were either object + body part + touch or object + body part + toss sequences. Additionally, filler trials were used, as in Experiment 1.

Each of five test sessions consisted of 26 trials: 10 touch trials, 10 toss trials, and 6 filler trials, arranged quasi-randomly. During each session, each of the 10 body-part symbols was used once with 
the touch action and once with the toss action. Additionally, each of the five objects was paired once with the touch action and once with the toss action. Thus, over the five sessions, there were 100 bodypart trials, each a unique combination of the five objects, 10 bodypart symbols, and two actions. All other conditions were the same as in Experiment 1A.

\section{Results and Discussion}

The top three panels of Figure 4 give examples of the dolphin's toss responses to three different baseline objects (surfboard, Frisbee, ball) using three different body parts (tail, melon, rostrum) in object + body part + toss sequences. Again, the clarity of the responses is apparent.

Elele's performance on the toss sequences is summarized in Table 3. Data for touch trials are not shown, but Elele responded wholly correctly to $45(90 \%)$ of the threepart touch sequences, making only three body-part errors (melon once and genital twice) and two object errors. She used the touch response in all cases. These performance levels were comparable to the performance levels for the touch sequences of Experiment 1C, when the left-right requirement was finally removed. In contrast, Table 3 shows that Elele responded wholly correctly to only 34 $(68 \%)$ of the 50 object + body part + toss sequences, significantly above chance $(p<.001)$ but significantly below her performance level on object + body part + touch sequences $\left[\chi^{2}(1, N=100)=11.12, p<.005\right]$. There were no object errors during toss sequences and only two during the touch sequences. Clearly, Elele had no difficulty in selecting the referenced object, regardless of the body part referred to or the action required.

Elele used the referenced body part on $38(76 \%)$ of the 50 trials given. She used 7 of the 10 designated body parts correctly on her first attempt to toss objects with that body part (considering tail and leg as separate attempts) $(p<.0001)$, again evidencing her ability to adapt her body-part responses spontaneously to new conditions or new requirements. Elele's body-part confusion errors during toss sequences are listed in Table 4. Bodypart errors were restricted to 5 parts: belly on all five sequences, genital on three, side on two, and rostrum and dorsal on one each. All other body parts were used correctly. The difficulty with belly did not seem to be in the dolphin's understanding of that body part, inasmuch as belly was responded to without error in all five touch sequences in Experiment 2A and in 15 of 18 touch trials during Experiment 1 (Table 1). Rather, Elele seemed unable to use her belly to toss objects, defaulting instead to three different body parts. The vertical, erect posture that we required for the belly response, exhibited reliably during touch sequences, was never assumed by the dolphin during comparable toss sequences. Overall, there were significantly more body-part errors during toss trials than during touch trials $\left[\chi^{2}(1, N=100)=5.02, p<.025\right]$.

\section{Experiment 2B}

In Experiment 2B, we added the display option to the required various body-part functions. Displaying her various body parts was not a new task for Elele. As we noted earlier, displays of all but melon were part of her routine husbandry behaviors or were used during informal training. The new task for Elele was to decide within the same testing session which body-part act to perform—-touch, toss, or display — depending on the particular gestural sequence given her.

\section{Method}

Testing was completed in a single session of 25 trials: 10 display trials (one per body-part symbol), 5 touch trials, 5 toss trials, and 5 filler trials. These different conditions were arranged in a quasirandom sequence with the constraint that there were no more than two display trials in succession. A different set of five body parts was used for touch sequences (mouth, belly, dorsal, side, and genital) than was used for toss sequences (rostrum, melon, pectoral fin, tail, and leg). The five baseline objects were again used, and all were floating. Elele received no prior preparation for the display trials. They were simply inserted among the other types of trials for the first time in Experiment 2B.

\section{Results and Discussion}

The bottom two panels of Figure 4 show the dolphin displaying two body parts (dorsal fin, genital) in body part + display sequences. In response to the gestural sequence dorsal display, Elele turned parallel to the tank wall, ventral side down, and raised her dorsal fin high in the air. For genital display, she turned on her back and raised her genital area above the water surface.

Elele made only a single error across the 10 display trials (see Table 3). She incorrectly revealed her belly (in the vertical, ventral forward position) when asked to display her rostrum. Since there was only one display trial given with each body part, each trial was a first occurrence and revealed Elele's ability to display the referenced body part in this new context, including melon, which was new to the display sequence. There were no errors to the 5 touch and 5 toss trials or to the 5 filler trials.

\section{Experiment 2C}

In Experiment 2C, we contrasted body-part trials using touch, toss, or display with those using shake. As noted earlier, Elele's previous experience with body part + shake sequences had been limited to her rostrum.

\section{Method}

There were two testing sessions, each of 30 trials. At each session, there were 10 shake sequences, 5 touch sequences, 5 toss sequences, 5 display sequences, and 5 filler trials. As in Experiment $2 \mathrm{~B}$, at each testing session, a different set of five body parts was used for touch sequences than was used for toss sequences; however, over the two sessions, all 10 body-part references appeared once in a touch sequence and once in a toss sequence. The five baseline objects were again all floating. In addition, over the two sessions, each of the 10 possible display sequences appeared once. For shake sequences, however, all 10 possible sequences, each using a different body-part reference, were given once at each session, or two times altogether. Elele received no prior preparation for the shake trials. As was the case for display sequences in Experiment $2 \mathrm{~B}$, shake sequences were simply inserted among the other types of trials for the first time in Experiment $2 \mathrm{C}$. 


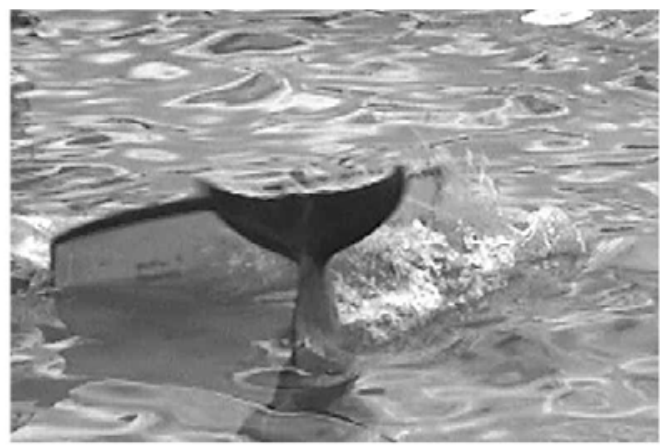

SURFBOARD TAIL TOSS

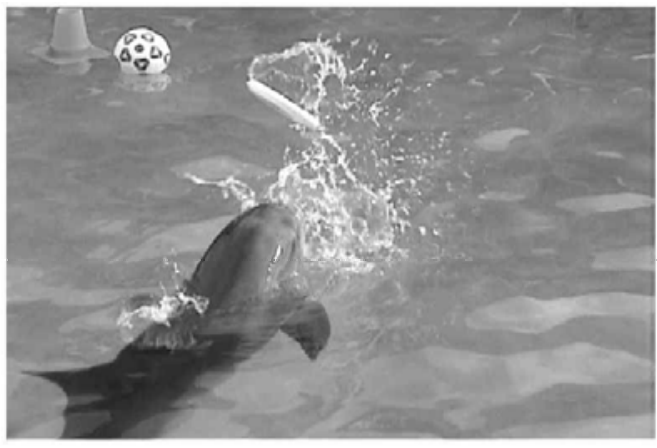

FRISBEE MELON TOSS

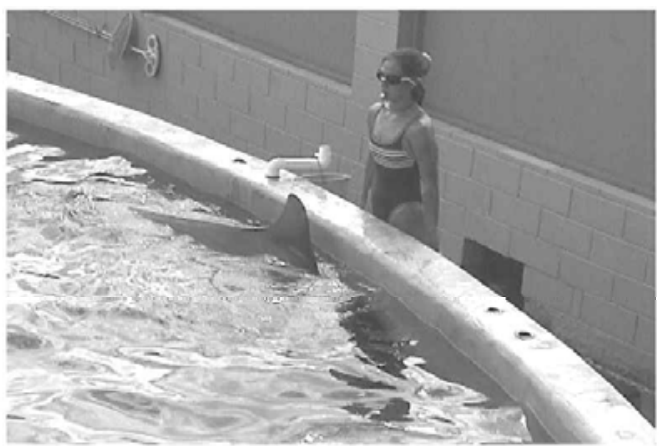

DORSAL FIN DISPLAY

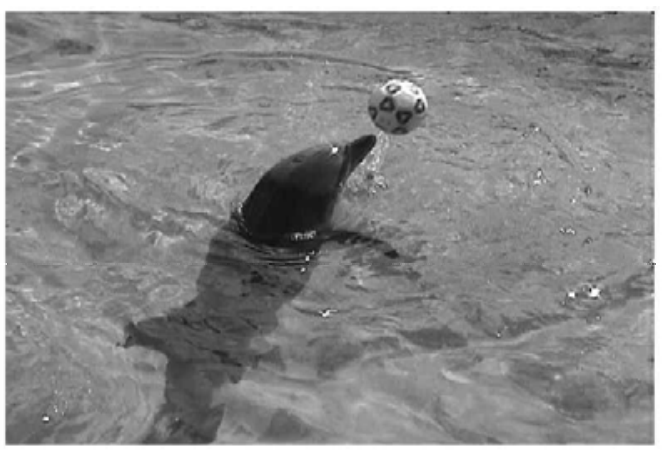

BALL ROSTRUM TOSS

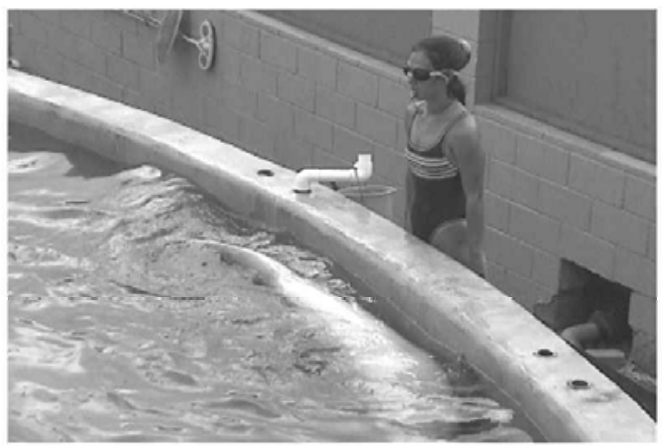

GENITAL DISPLAY

Figure 4. Examples of the dolphin Elele responding in Experiments $2 \mathrm{~A}$ and 2B. The top three panels are examples of the dolphin's toss response to three different objects using three different body parts in response to $o b$ ject + body part + toss sequences. The bottom two panels are examples of the dolphin displaying her dorsalfin (left) and genitals (right) in response to body part + display sequences. Both panels are still images captured from individual frames of the digital video records obtained during testing.

\section{Results and Discussion}

Examples of shake responses are not illustrated because their dynamic character cannot be captured in a single frame. As can be seen in Table 3, Elele always performed the shake response when required and used the correct body part on 16 of the 20 shake sequences. As can be seen in Table 4, all four of Elele's body-part errors were to shake her rostrum (a behavior previously highly familiar to her) instead of the referenced body part. Two of these errors involved a request to shake her melon. Although both the melon shake and the rostrum shake involve a back-and-forth movement of the head, the melon response requires that the head and rostrum be hunched downward while shaking, whereas the rostrum response requires that the head and rostrum be held erect. The observer judging Elele's responses did not see a hunched posture and labeled the response as rostrum shake. Of the eight body parts new to the shake sequence, Elele 
Table 3

Number of correct responses to Object + Body Part + Toss Sequences, Body Part + Display Sequences, and Body Part + Shake Sequences by Component Elements of the Sequence for Each Listed Body Part in Experiments 2A, 2B, and 2C

\begin{tabular}{|c|c|c|c|c|c|c|c|c|}
\hline \multirow[b]{2}{*}{ Body Part } & \multicolumn{4}{|c|}{$\begin{array}{c}\text { Experiment } 2 \mathrm{~A}(n=5) \\
\text { Toss Sequences }\end{array}$} & \multicolumn{2}{|c|}{$\begin{array}{c}\text { Experiment 2B }(n=1) \\
\text { Display Sequences } \\
\end{array}$} & \multicolumn{2}{|c|}{$\begin{array}{c}\text { Experiment } 2 \mathrm{C}(n=2) \\
\text { Shake Sequences }\end{array}$} \\
\hline & Object & $\begin{array}{l}\text { Body } \\
\text { Part }\end{array}$ & Toss & $\begin{array}{c}\text { Whole } \\
\text { Sequence }\end{array}$ & $\begin{array}{l}\text { Body } \\
\text { Part }\end{array}$ & Display & $\begin{array}{l}\text { Body } \\
\text { Part }\end{array}$ & Shake \\
\hline Rostrum & $5+$ & $4+$ & $5+$ & $4+$ & $0-$ & $1+$ & $2+$ & $2+$ \\
\hline Mouth & $5+$ & $5+$ & $2+$ & $2+$ & $1+$ & $1+$ & $2+$ & $2+$ \\
\hline Melon & $5+$ & $5+$ & $5+$ & $5+$ & $1+$ & $1+$ & $0-$ & $2+$ \\
\hline Belly & $5+$ & $0-$ & $4+$ & $0-$ & $1+$ & $1+$ & $1-$ & $2+$ \\
\hline Pec fin & $5+$ & $5+$ & $5+$ & $5+$ & $1+$ & $1+$ & $2+$ & $2+$ \\
\hline Dorsal & $5+$ & $4+$ & $4+$ & $3+$ & $1+$ & $1+$ & $2+$ & $2+$ \\
\hline Side & $5+$ & $3-$ & $5-$ & $3-$ & $1+$ & $1+$ & $2+$ & $2+$ \\
\hline Genital & $5+$ & $2-$ & $5+$ & $2-$ & $1+$ & $1+$ & $2+$ & $2+$ \\
\hline Tail & $5+$ & $5+$ & $5+$ & $5+$ & $1+$ & $1+$ & $2+$ & $2+$ \\
\hline Leg & $5+$ & $5+$ & $5+$ & $5+$ & $1+$ & $1+$ & $1-$ & $2+$ \\
\hline Total & $\begin{array}{c}50 \\
(100.0 \%)\end{array}$ & $\begin{array}{c}38 \\
(76.0 \%)\end{array}$ & $\begin{array}{c}45 \\
(90.0 \%)\end{array}$ & $\begin{array}{c}34 \\
(68.0 \%)\end{array}$ & $\begin{array}{c}9 \\
(90.0 \%)\end{array}$ & $\begin{array}{c}10 \\
(100.0 \%)\end{array}$ & $\begin{array}{c}16 \\
(80.0 \%)\end{array}$ & $\begin{array}{c}20 \\
(100.0 \%)\end{array}$ \\
\hline
\end{tabular}

Note-Maximum possible scores are 5, 1, and 2 for Experiments 2A, 2B, and 2C, respectively. Left and right were not used in Experiment 2. +, correct response on first trial; -, incorrect response.

shook six correctly (mouth, pectoral fin, dorsal, side, genital, and tail) on the first occasion in which they were referenced $(p<.0002)$.

There were no errors during the 10 display sequences or during the 10 touch sequences given during Experiment 2C (data not shown in Table 3). There were four body-part errors, however, during the 10 toss sequences, one each to rostrum, belly, side, and genital.

The results of Experiments 2A, 2B, and 2C, considered collectively, show remarkable flexibility in the dolphin's use of its various body parts. Clearly, Elele was able to direct her attention to the referenced body part and then reliably use that body part to perform the referenced action of four different possibilities. The only action that she did not produce correctly at least once was tossing an object with her belly.

\section{GENERAL DISCUSSION}

How well did Elele's performance meet with the conditions we stated for inferring an understanding that gestural symbols represented her body parts? These condi- tions were that (1) different body parts be associated with different symbols, (2) different symbolically referenced body parts be used in the same way, and (3) the same symbolically referenced body part be used in different ways. For Conditions 2 and 3, carrying out novel acts or using body parts in novel contexts strengthens any inference of referential understanding of body-part symbols. By fulfilling these conditions, evidence accrues that the symbols are indeed understood as references to body parts and not simply as discriminative stimuli for eliciting learned responses with body parts.

Condition 1 was satisfied by pairing different gestures with different body parts. Nine of Elele's body parts were selected and were associated with 10 different gestures (Elele's tail was associated with two synonymous gestures, glossed as tail and leg). In addition, in the initial experiments, Elele's left and right pectoral fin and her left and right side were each differentiated not by different gestures but by which of the trainer's arms, left or right, was used to produce the gesture.

Condition 2, using different body parts in the same way, was met throughout both experiments. In Experi-

Table 4

Body-Part Confusion Errors for Toss Sequences, Display Sequences, and Shake Sequences in Experiments 2A, 2B, and 2C, Respectively

\begin{tabular}{llcc}
\hline \multirow{2}{*}{$\begin{array}{l}\text { Referenced } \\
\text { Body Part }\end{array}$} & \multicolumn{3}{c}{ Body Part Used in Error } \\
\cline { 2 - 4 } Rostrum & Melon (1) & Experiment 2B & Experiment 2C \\
Belly & Rostrum (2), Melon (2), & Belly (1) & - \\
& Genital (1) & - & Rostrum (1) \\
Melon & - & - & Rostrum (2) \\
Side & Rostrum (2) & - & - \\
Dorsal & Genital (1) & - & - \\
Genital & Rostrum (1), Tail (2) & - & - \\
Leg & - & - & Rostrum (1) \\
\hline
\end{tabular}

Note-The number of times a body part was used in error shown in parentheses (e.g., in Experiment 2A, rostrum was used once in error and tail was used twice in error to toss an object when the referenced body part was in fact genital). Body parts not listed in the "Reference Body Part" column were always used without error. 
ment 1 , Elele successfully touched gesturally referenced objects with each of her gesturally referenced body parts, including her left and right body parts, on at least two of five attempts (most of the body parts were used successfully on four or on all five of the attempts). In Experiment 2 , eight of the nine body parts were used successfully to toss referenced objects, the exception being belly. Eight of the nine referenced body parts were successfully displayed, the exception being rostrum; eight of nine were shaken successfully at least once in two trials, the exception being melon. Significantly, six of the touch actions, six of the toss actions, eight of the shake actions, and one display action were associated with body parts that had not been used for those functions previously. In Experiment 1 , Elele used her different body parts on the first occasion in which each was referred to in a three-part object + body part + touch sequence on 31 of 34 opportunities. Each occasion was either a unique combination of a body-part reference and an object reference or an object and a body-part reference previously encountered but now used in a unique context, as in responding to suspended objects rather than floating objects. Elele's primary difficulty in Experiment 1 was in distinguishing reliably between her left and right pectoral fin and her left and right side when touching objects. During Experiments 1A and $1 \mathrm{~B}$, Elele used her right body part on 6 of the $16 \mathrm{oc}-$ casions when a left body part was referenced. Because of this difficulty, left-right references were no longer used in Experiment 1C. Of course, left-right body-part discriminations can be difficult, even for humans. Young children typically do not attain reliable left-right bodypart discriminations until after approximately the age of 5 (Swanson \& Benton, 1955).

Evidence that Elele's performance met with Condition 3, using the same referenced body part in different ways, extended throughout both experiments. In Experiment 1, we found that Elele was able to extend her touch responses, initially tested with five floating arbitrary objects, to the three translocatable objects (Hiapo, person, and water). Successful performance required that Elele modify the form of her touch response somewhat for these different objects. Modifications of her touch response were also required and successfully made when touching suspended objects-for example, by stretching her rostrum upward to reach a suspended object rather than extending it forward at water level to contact a floating object (Figure 3 ).

These various appropriate adjustments or modifications of her touch responses suggest that Elele understood touching as a concept and not as simply a learned stereotyped motor act. Other work with bottlenosed dolphins also suggests that learned motor acts may develop into concepts. For example, Herman et al. (1984) trained the dolphin Akeakamai to swim under a floating object in response to a unique gestural symbol glossed as under. Later, for the first time, an object was placed flat on the bottom of the tank floor, and Akeakamai was given the gesture under. She spontaneously lifted the object off the floor with her rostrum and then quickly swam under it, thereby altering the state of the object to make it possible to carry out the requested action. This same type of response accommodation continued to be made to other sunken objects. Herman et al. referred to this concept as underness and gave additional examples of learned motor acts developing into concepts (e.g., throughness and overness).

The most compelling evidence in support of meeting Condition 3 is found in the successful contrasts in Experiment 2 among the behaviors of touching, tossing, displaying, or shaking a referenced body part. Seven of the nine body parts were used successfully at least once with each of the four actions. The remaining two, melon and belly, were used successfully with three of the four actions (Elele failed to shake her melon or, as was noted, toss with her belly). Many of the behaviors were new to Elele's experience, but most were carried out correctly on Elele's first attempt.

Successful execution of these actions required semantic processing of both the body-part gestures and the action gestures. Semantic processing requires, in the least, that two or more objects or two or more actions be contrasted. In Experiment 1, for example, only the touch response was required. It could be claimed, therefore, that the touch symbol was not processed semantically but was simply a releaser for that particular action. In Experiment 2 , however, the dolphin could not prepare or predict the type of response that would be required after a body-part gesture had been given but had to differentiate and process semantically the particular succeeding action gesture. The need to use semantic contrasts to make strong inferences about the referential understanding of symbols has been emphasized elsewhere (e.g., see the contrast between the actions fetch and in as described by Herman et al., 1984; also see Herman \& Uyeyama, 1999).

Even though some of the required novel body-part actions seem difficult to execute, and possibly even difficult to conceive of, such as tossing an object with the dorsal fin, side, or genitals, Elele was nonetheless able to perform each of these acts successfully at least two or more times in five attempts. Elele was also able to shake each of these same body parts successfully on both of her two attempts. Experiment 2C, which combined all four motor acts-touch, toss, display, and shakewithin a single block of trials, established the flexibility and adaptability of Elele's body-part responses.

Theoretically, the dolphin's understanding of symbolic references to her body parts provides inferential evidence for what has been termed a body image, conceived of as the conscious representational system (or systems) that includes conceptual knowledge (both semantic and topographical) about one's body parts and their interrelations (Coslett, 1998; Gallagher, 1986, 1995). This representational system allows for identification of one's own body parts, for acts of intentional control of those body parts and for conscious awareness of those acts.

In humans, compelling evidence for a body-image concept is found in reports of brain dysfunctions that selectively limit conscious awareness of one's body parts 
without impairing those aspects of motor control not requiring conscious attention, such as postural control (e.g., Heilman, Valenstein, \& Watson, 1993; Ogden, 1985; Sirigu, Grafman, Bressler, \& Sunderland, 1991). For example, in autotopagnosia- a condition associated with lesions in the parietal region of the left hemisphere (Ogden, 1985; Reed \& Farah, 1995; Sirigu et al., 1991) patients cannot locate the body part being named by the examiner, on themselves, on the examiner, on a doll, or on a picture of a person. That the deficit is not simply semantically based is shown by the patient's ability, nonetheless, to name the body part being pointed to by the examiner (Ogden, 1985; Sirigu et al., 1991). The identification and conscious awareness and control of one's own body parts thus seem dependent on the development and maintenance of a body image represented in one or more places in the brain. The developing ability of the infant to selectively attend to or activate representations of its body parts has been postulated as a precursor to the development of the self-concept or self-consciousness (Kinsbourne, 1995; cf. Martin, 1995).

Elele's responses revealed both semantic and topographical knowledge of her body parts. The evidence seems strong that Elele was able to identify and perceive her body parts as objects over which she had conscious motor control. She not only understood symbolic gestural references to any of nine different body parts (including synonymous gestures for her tail) but also successfully used the referenced body parts to carry out a variety of functions or motor acts as specified by gestural symbols.

Can we infer that Elele was consciously aware of her motor acts, consistent with the concept of a body-image representational system? Other work with Elele suggests just that. The ability of Elele (and other dolphins) to imitate the motor behaviors of a "demonstrator" dolphin or of a human (see reviews in Herman, in press, and Herman et al., 1993) requires attention to the motor behaviors of another, mental representation of that behavior, and conscious planful execution of an imitative or analogous act. Further evidence for Elele's conscious awareness of her motor acts can also be inferred from demonstrations of Elele's ability to repeat a behavior on command (Mercado et al., 1998; Mercado et al., 1999). In these studies, Elele repeated a behavior just executed only if given a particular gestural symbol glossed as repeat. Some of the behaviors were simple motor acts, and some were actions on objects, as was the case in the present experiments. For example, in the Mercado et al. (1998) study, Elele successfully repeated 28 of 32 different motor behaviors on at least three of the four occasions tested ( $p<.05$, for each behavior performed at this level). Given these results, it seems probable that Elele could have also repeated many of the behaviors she performed in the present study, although we did not test for that capability. Altogether, then, there seems reasonably good suggestive evidence for crediting Elele, in theory, with a body-image representational system analogous to that theorized for humans for the conscious awareness and conscious control of one's own body parts (Coslett, 1998; Gallagher, 1986, 1995).

\section{REFERENCES}

Bermudez, J. L., Marcel, A., \& Eilan, N. (Eds.) (1995). The body and the self. Cambridge, MA: MIT Press.

Bronowski, J., \& BelugGi, U. (1970). Language, name and concept. Science, 168, 669-673.

Call, J., \& Tomasello, M. (1994). Production and comprehension of referential pointing by orangutans (Pongo pygmaeus). Journal of Comparative Psychology, 108, 307-317.

Coslett, H. B. (1998). Evidence for a disturbance of the body schema in neglect. Brain \& Cognition, 37, 527-544.

Gallagher, S. (1986). Body image and body schema: A conceptual clarification. Journal of Mind \& Behavior, 7, 541-554.

Gallagher, S. (1995). Body schema and intentionality. In J. L. Bermudez, A. J. Marcel, \& N. Eilan (Eds.), The body and the self (pp. 225-244). Cambridge, MA: MIT Press.

Gardner, B. T., \& Gardner, R. A. (1971). Two-way communication with an infant chimpanzee. In A. M. Schrier \& F. Stollnitz (Eds.), Behavior of nonhuman primates (Vol. 4, pp. 117-184). New York: Academic Press.

Gauker, C. (1990). How to learn language like a chimpanzee. Philosophical Psychology, 3, 31-53.

Heilman, K. M., Valenstein, E., \& Watson, R. T. (1993). Neglect and related disorders. In K. M. Heilman \& E. Valenstein (Eds.), Clinical neuropsychology (pp. 279-336). New York: Oxford University Press.

Herman, L. M. (1987). Receptive competencies of language-trained animals. In J. S. Rosenblatt (Ed.), Advances in the study of behavior (Vol. 17, pp. 1-60). Petaluma, CA: Academic Press.

Herman, L. M. (in press). Vocal, social, and self-imitation by bottlenosed dolphins. In C. Nehaniv \& K. Dautenhahn (Eds.), Imitation in animals and artifacts. Cambridge, MA: MIT Press.

Herman, L. M., Abichandani, S. L., ElhajJ, A. N., Herman, E. Y. K., SANCHEZ, J. L., \& PACK, A. A. (1999). Dolphins (Tursiops truncatus) comprehend the referential character of the human pointing gesture. Journal of Comparative Psychology, 113, 1-18.

Herman, L. M., \& Forestell, P. H. (1985). Reporting presence or absence of named objects by a language-trained dolphin. Neuroscience \& Biobehavioral Reviews, 9, 667-681.

Herman, L. M., Pack, A. A., \& Hoffmann-Kuhnt, M. (1998). Seeing through sound: Dolphins perceive the spatial structure of objects through echolocation. Journal of Comparative Psychology, 112, 292305.

Herman, L. M., Pack, A. A., \& Morrel-Samuels, P. (1993). Representational and conceptual skills of dolphins. In H. L. Roitblat, L. M. Herman, \& P. E. Nachtigall (Eds.), Language and communication: Comparative perspectives (pp. 273-298). Hillsdale, NJ: Erlbaum.

Herman, L. M., Richards, D. G., \& Wolz, J. P. (1984). Comprehension of sentences by bottlenosed dolphins. Cognition, 16, 129-219.

Herman, L. M., \& Uyeyama, R. K. (1999). The dolphin's grammatical competency: Comments on Kako (1998). Animal Learning \& Behavior, 27, 18-23.

Hocketт, C. F. (1960). Logical considerations in the study of language. In W. E. Lanyon \& W. N. Tavolga (Eds.), Animal sounds and communication (pp. 392-430). Washington, D.C.: American Institute of Biological Sciences.

Kinsbourne, M. (1995). Awareness of one's own body: An attentional theory of its nature, development, and brain basis. In J. L. Bermudez, A. Marcel, \& N. Eilan (Eds.), The body and the self (pp. 205-223). Cambridge, MA: MIT Press.

Leavens, D. A., \& Hopkins, D. A. (1998). Intentional communication by chimpanzees: A cross-sectional study of the use of referential gestures. Developmental Psychology, 34, 813-822.

MacWhinney, K., Cermak, S. A., \& Fisher, A. (1987). Body part identification in 1- to 4-year-old children. American Journal of Occupational Therapy, 41, 454-459.

Martin, M. G. F. (1995). Bodily awareness: A sense of ownership. In J. L. Bermudez, A. Marcel, \& N. Eilan (Eds.), The body and the self (pp. 267-289). Cambridge, MA: MIT Press. 
Mercado, E., III, Murray, S. O., Uyeyama, R. K., Pack, A. A., \& Herman, L. M. (1998). Memory for recent actions in the bottlenosed dolphin(Tursiops truncatus): Repetition of arbitrary behaviors using an abstract rule. Animal Learning \& Behavior, 26, 210-218.

Mercado, E., III, Uyeyama R. K., Pack, A. A., \& Herman, L. M. (1999). Memory for action events in the bottlenosed dolphin. Animal Cognition, 2, 17-25.

OGDEN, J. A. (1985). Autotopagnosia: Occurrence in a patient without nominal aphasia and with an intact ability to point to parts of animals and objects. Brain, 108, 1009-1022.

Pack, A. A., \& Herman, L. M. (1995). Sensory integration in the bottlenosed dolphin: Immediate recognition of complex shapes across the senses of echolocation and vision. Journal of the Acoustical Society of America, 98, 722-733.

Patterson, F. G. P., \& Cohn, R. H. (1994). Self-recognition and selfawareness in lowland gorillas. In S. T. Parker, R. W. Mitchell, \& M. L. Boccia (Eds.), Self-awareness in animals and humans: Developmental perspectives (pp. 273-300). New York: Cambridge University Press.

Povinelli, D. J., Reaux, J. E., Bierschwale, D. T., Allain, A. D., \& Simon, B. B. (1997). Exploitation of pointing as a referential gesture in young children, but not adolescent chimpanzees. Cognitive Development, 12, 423-461.

REed, C. L., \& FARAH, M. J. (1995). The psychological reality of the body schema: A test with normal participants. Journal of Experimental Psychology: Human Perception \& Performance, 21, 334-343.

Rumbaugh, D. M. (Ed.) (1977). Language learning by a chimpanzee: The Lana project. New York: Academic Press.

Savage-Rumbaugh, E. S. (1984). Acquisition of functional symbol usage in apes and children. In H. L. Roitblat, T. G. Bever, \& H. S. Terrace (Eds.), Animal cognition (pp. 291-310). Hillsdale, NJ: Erlbaum.
SAVAge-Rumbaugh, E. S. (1986). Ape language: From conditioned response to symbol. New York: Columbia University Press.

Savage-Rumbaugh, E. S., Murphy, J., Sevcik, R. A., Brakke, K. E., Williams, S. L., \& Rumbaugh, D. M. (1993). Language comprehension in ape and child. Monographs of the Society for Research in Child Development, 58 (Serial No. 233), 1-221.

Siegel, S., \& CASTEllan, N. J., JR. (1988). Nonparametric statistics for the behavioral sciences. New York: McGraw-Hill.

Sirigu, A., Grafman, J., Bressler, K., \& Sunderland, T. (1991). Multiple representations contribute to body knowledge processing: Evidence from a case of autotopagnosia Brain, 114, 629-642.

SWAnson, R, \& Benton, A. L. (1955). Some aspects of the genetic development of right-left discrimination. Child Development, 26, 123-133.

Terrace, H. S. (1979). Nim. New York: Knopf.

Terrace, H. S. (1984). "Language" in apes. In R. Harré \& V. Reynolds (Eds.), The meaning of primate signals (pp. 179-207). Cambridge: Cambridge University Press.

Witt, A., Cermak, S., \& Coster, W. (1990). Body part identification in 1- to 2-year-old children. American Journal of Occupational Therapy, 44, 147-153.

\section{NOTE}

1. This probability and all subsequently listed probabilities for observing the initial body-part performance levels by chance alone use the cumulative binomial test. Chance probability is set at .09 when there is a choice among 11 body parts (including left and right parts, but counting leg and tail only once) and at .11 when there is a choice among nine body parts (left and right parts no longer referred to). These chance probabilities assume a random choice of body part.

\section{APPENDIX}

To assess the reliability of the judgments of the observer labeling Elele's responses, two additional raters independently watched selected video clips of Elele's performance and described her behavior using the same system of labeling as that used by the observer. The raters were two graduate students who did not participate in any of the experiments described in this paper but who were highly familiar with the dolphin's responses to various types of gestural instructions and the general form of the grammatical sequences used to generate those instructions. A 25\% sample was made of the dolphin's responses in each experiment and each part of the experiment. Both correct responses and error responses were included, each an approximate $25 \%$ sample. The video clips were edited to reveal only the dolphin's responses (i.e., the trainer's gestures were not shown). Because the video clips are not as clear as the live performance, the raters were allowed to view a video clip twice if they requested it. The raters' responses were then compared with those of the observer in two ways. First, we tabulated the number of sequences that each rater labeled in exactly the same way as the observer. Second, Cohen's Kappa (Siegel \& Castellan, 1988) was computed separately for each component part of a sequence: object, body part, and action. Table A1 shows the number of judgments of each rater that were identical to those of the observer, for each of the two experiments. The agreement is very high: Rater 1 labeled 62 of 67 sequences exactly as did the observer, and Rater 2 labeled 65 sequences the same way as did the observer.

Table A2 summarizes the results for Cohen's Kappa. Cohen's Kappa was computed separately for each component of the se- quence object + body part + action (touch or toss) or body part + action (display or shake). Again, results are shown separately for each rater. In each case, the rater's judgment of the component is compared with the observer's judgment. The higher the Kappa value, the closer the agreement between raters, with a Kappa of 1.0 indicating perfect agreement. Table A2 reveals perfect agreement of both raters with the observer for objects selected by the dolphin and for actions taken. The only discrepancies were in body-partjudgments, but the agreement was still high. In Table A2, Kappas of .82 and .89 represent two differences in body-part judgments (of 12 and 20 judgments, respectively), and Kappas of .93 and .94 represent one difference (of 15 and 20 judgments, respectively). Differences for Rater 1 included stating right pectoralfin instead of right side, rostrum instead of belly, melon instead of rostrum (twice), and dorsal instead of side (Experiment 2). In all cases, the observer's judg-

Table A1

The Number of Sequences Each Rater Scored Exactly the Same as the Observer

\begin{tabular}{cccc}
\hline & \multirow{2}{*}{$\begin{array}{c}\text { Number of } \\
\text { Experiment }\end{array}$} & \multicolumn{2}{c}{ Number Judged the Same } \\
\cline { 3 - 4 } & Video Clip Sequences & Rater 1 & Rater 2 \\
\hline 1A & 15 & 14 & 15 \\
1B & 12 & 10 & 11 \\
1C & 20 & 20 & 20 \\
2 & 20 & 18 & 19 \\
Total & 67 & $62(92.5 \%)$ & $65(97.0 \%)$ \\
\hline
\end{tabular}


APPENDIX (Continued)

Table A2

Cohen's Kappa for Each Rater for Each Component Part of a Three-Part or Two-Part Sequence

\begin{tabular}{ccccccccc}
\hline & & \multicolumn{3}{c}{ Rater 1 } & & \multicolumn{3}{c}{ Rater 2 } \\
Experiment & $n$ & Object & Body Part & Action & & Object & Body Part & Action \\
\hline 1A & 15 & 1.0 & 0.93 & 1.0 & & 1.0 & 1.0 & 1.0 \\
1B & 12 & 1.0 & 0.82 & 1.0 & & 1.0 & 0.82 & 1.0 \\
1C & 20 & 1.0 & 1.0 & 1.0 & & 1.0 & 1.0 & 1.0 \\
2 & 20 & 1.0 & 0.89 & 1.0 & & 1.0 & 0.94 & 1.0 \\
\hline
\end{tabular}

ment corresponded to the body part referenced gesturally. For Rater 2, the differences were judging left pectoralfin instead of left side, melon instead of rostrum (the same difference as Rater 1), and dorsal instead of side (the same difference as Rater 1). Again, the observer's judgments corresponded to the refer- enced body part. Altogether, considering that judgments made from the video screen were likely more difficult than those made live, the high degree of correspondence found between each rater and observer strongly validates the objectivity of the observer and the reliability of the judgments made.

(Manuscript received November 2, 2000;

revision accepted for publication April 13, 2001.) 